\title{
Surgical management and long-term outcomes of intracranial giant cell tumors: a single-institution experience with a systematic review
}

\author{
*Jian-Cong Weng, MD,' Da Li, MD,' Liang Wang, MD, PhD,' Zhen Wu, MD, PhD,1 Jun-Mei Wang, MD, ${ }^{2}$ \\ Gui-Lin Li, MD, ${ }^{2}$ Wang Jia, MD, PhD, ${ }^{1}$ Li-Wei Zhang, MD, PhD, ${ }^{1}$ and Jun-Ting Zhang, MD'1
}

${ }^{1}$ Department of Neurosurgery, Beijing Tiantan Hospital, Capital Medical University, Beijing; and 2Department of Neuropathology, Beijing Neurosurgical Institute, Beijing, People's Republic of China

\begin{abstract}
OBJECTIVE Intracranial giant cell tumors (GCTs) are extremely rare neoplasms with dismal survival and recurrence rates. The authors aimed to confirm independent adverse factors for progression-free survival (PFS) and to propose an optimal treatment algorithm.
\end{abstract}

METHODS The authors reviewed the clinical data of 43 cases of intracranial GCTs in their series. They also reviewed 90 cases of previously reported GCTs in the English language between 1982 and 2017 using Ovid MEDLINE, Embase, PubMed, and Cochrane databases with keywords of "giant cell tumor" or "osteoclastoma" and "skull," "skull base," "temporal," "frontal," "sphenoid," or "occipital." These prior publication data were processed and used according to PRISMA (Preferred Reporting Items for Systematic Reviews and Meta-Analyses) guidelines. Aforementioned risk factors for the authors' series and the pooled cases were evaluated in patients not lost to follow-up ( $m=38$ and $n=128$, respectively).

RESULTS The authors' cohort included 28 males and 15 females with a mean age of 30.5 years. Gross-total resection (GTR) was achieved in 15 (34.9\%) patients. Fifteen patients (39.5\%) who did not undergo GTR received postoperative radiotherapy with a mean total dose of $54.7 \pm 4.1 \mathrm{~Gy}$. After a mean follow-up of 71.3 months, $12(31.6 \%)$ patients experienced recurrence, and 4 (10.5\%) died of disease. The actuarial 5-year PFS and overall survival (OS) were 68.6\% and $90.0 \%$ in the authors' cohort, respectively. A multivariate Cox regression analysis verified that partial resection (HR $7.909,95 \% \mathrm{Cl} 2.296-27.247, \mathrm{p}=0.001$ ), no radiotherapy (HR 0.114, 95\% Cl 0.023-0.568, $p=0.008$ ), and Ki-67 $\geq 10 \%$ ( $H R 7.816,95 \% \mathrm{Cl} 1.584-38.575, p=0.012$ ) were independent adverse factors for PFS. Among the 90 cases in the literature, GTR was achieved in $49(54.4 \%)$ cases. Radiotherapy was administered to $33(36.7 \%)$ patients with a mean total dose of $47.1 \pm 5.6 \mathrm{~Gy}$. After a mean follow-up of 31.5 months, recurrence and death occurred in $17(18.9 \%)$ and 5 (5.6\%) cases, respectively. Among the pooled cases, the 5-year PFS and OS were $69.6 \%$ and $89.2 \%$, respectively. A multivariate model demonstrated that partial resection ( $\mathrm{HR} 4.792,95 \% \mathrm{Cl} 2.909-7.893, \mathrm{p}<0.001$ ) and no radiotherapy (HR 0.165, 95\% Cl 0.065-0.423, p < 0.001) were independent adverse factors for poor PFS.

CONCLUSIONS GTR and radiotherapy were independent favorable factors for PFS of intracranial GCTs. Based on these findings, GTR alone or GTR plus radiotherapy was advocated as an optimal treatment; otherwise, partial resection plus radiotherapy with a dose $\geq 45 \mathrm{~Gy}$, if tolerable, was a secondary alternative. Lack of randomized data of the study was stressed, and future studies with larger cohorts are necessary to verify these findings.

Systematic review no.: CRD42018090878 (crd.york.ac.uk/PROSPERO/)

https://thejns.org/doi/abs/10.3171/2018.4.JNS1849

KEYWORDS bone giant cell tumor; intracranial; treatment algorithm; radiotherapy; oncology

ABBREVIATIONS EMA = epithelial membrane antigen; EMPT = estimated mean PFS time; GCRG = giant cell reparative granuloma; GCT = giant cell tumor; GKRS = Gamma Knife radiosurgery; GTR = gross-total resection; IMRT = intensity-modulated radiotherapy; KPS = Karnofsky Performance Scale; OS = overall survival; PFS = progression-free survival; $\mathrm{PR}=$ partial resection; $\mathrm{STR}=$ subtotal resection; TMJ = temporomandibular joint.

SUBMITTED January 9, 2018. ACCEPTED April 23, 2018.

INCLUDE WHEN CITING Published online October 12, 2018; DOI: 10.3171/2018.4.JNS1849.

${ }^{*}$ J.C.W. and D.L. contributed equally to this work. 
$\mathrm{G}$ IANT cell tumors (GCTs) are rare neoplasms, representing approximately $5 \%$ of skeletal tumors. Although benign, these tumors can be locally aggressive with a recurrence rate of up to $30 \%$, if managed merely via an intralesional resection. ${ }^{13,15,37}$ The majority of these tumors are located in the epiphyses of long bones with localized osteolysis, which account for 75\%-90\% of GCTs. ${ }^{19,20}$ Enneking's ${ }^{32}$ clinical staging system classified GCTs into 3 stages with various $\mathrm{Ki}-67$ indices. Because primary GCTs of the cranium are extremely rare ( $<1 \%$ of all GCTs), ${ }^{23,28}$ management of these tumors remains a matter of debate. The National Comprehensive Cancer Network (NCCN) has not proposed a treatment strategy for intracranial GCTs. A recent study performed by Zhang et al. ${ }^{44}$ claimed that non-gross-total resection (GTR) and no postoperative radiotherapy are adverse factors for progression-free survival (PFS); however, no specific treatment strategies were proposed. Therefore, we retrospectively reviewed patients with pathologically confirmed GCTs who underwent surgical treatment at our institution, and we also performed an extensive literature review. In the present study, we aimed to evaluate the risk factors for PFS and to propose a treatment algorithm for GCTs based on the pooled analysis of individual patient data.

\section{Methods \\ Patient Population}

Forty-three patients with intracranial GCTs who presented to our institution between 2002 and 2016 were identified (Table 1). The clinical charts and radiographs were reviewed. Pre- and postoperative functional status was evaluated using the Karnofsky Performance Scale (KPS). The following information was recorded: age, sex, preoperative main complaint, symptom duration, tumor traits, surgical findings, extent of resection, and followup data (including postoperative radiotherapy, PFS, and overall survival [OS]). Tumor size was evaluated and expressed as the lesion-equivalent diameter $(\mathrm{abc})^{1 / 3}$ (cube root of the product of these 3 diameter values), where a, $\mathrm{b}$, and c are mutually orthogonal and represent the maximum diameters (width, thickness, and height) measured on axial, sagittal, and coronal MRI, respectively. Both preand postoperative tumor volumes were calculated using the cubature formula: volume $=(\mathrm{a} \times \mathrm{b} \times \mathrm{c}) / 2$. The extent of resection was determined by volumetric evaluation based on postoperative contrasted MRI scans and was recorded as GTR (without residue), subtotal resection (STR; with 90\%-99\% excision of the lesion), or partial resection (PR; with $<90 \%$ excision of the lesion). The tumor consistency was semiquantitatively defined and was classified into 3 subtypes: 1) soft/crisp, able to be aspirated by suction; 2) tenacious, unable to be aspirated but cuttable with scissors; and 3) hard, not cuttable with scissors, and exhibiting calcification on CT scans or containing calcified component. The degree of blood supply was used to qualitatively describe the various extent of tumor vascularization. During intracapsular resection, "moderate" blood supply was defined as bleeding from tumor tissue that could be cleaned out immediately using a 7- or 9-F suction tube with occlusion of the air hole, while "abundant" was defined as intraoperative heavy tumor bleeding that could be cleaned out immediately by a suction tube of at least 10 or $12 \mathrm{~F}$ in size with occlusion of the air hole.

We proposed a modified imaging stage standard for intracranial GCTs based on a prior study. ${ }^{41}$ Stage I tumors remain epidural and confined to a small area within bone; stage II tumors expand to the cortex and break the dura mater but have a clear boundary with brain tissues; and stage III tumors manifest as intradural growth and extend into the brain tissues or both extra- and intracranial growth. Receiver operating characteristic curve analysis was used to determine the optimal cutoff value of the $\mathrm{Ki}$ 67 index for predicting recurrence (cutoff $=10 \%$, sensitivity 0.750 , specificity 0.839 ). Therefore, a cutoff $\mathrm{Ki}-67$ index of $10 \%$ was applied to distinguish malignant from less malignant GCTs, and coincidentally it was within the range $(7.5 \%-14 \%)$ of that reported by Antal et al. ${ }^{1}$ This study was approved by the Beijing Tiantan Hospital Research Ethics Committee.

\section{Pooled Analysis of Prior Published Cases}

A literature review of skull GCTs in the English language was performed using the Ovid MEDLINE, Embase, PubMed, and Cochrane databases between 1982 and 2017 by 2 independent review authors. The keywords used in the search were "giant cell tumor" or "osteoclastoma" and "skull," "skull base," "temporal," "frontal," "sphenoid," or "occipital." Inclusion criteria were pathological diagnosis of a GCT; intracranial and/or skull location; and detailed information of treatment, neurological outcome, status of recurrence, or death. Exclusion criteria were location other than intracranial and/or skull, unavailable or incomplete clinical data, basic research rather than clinical report without detailed clinical data, undefined pathological diagnosis, and/or duplicated report. We further reviewed all of the references provided in the identified publications and incorporated the pertinent citations. The prior publication data were processed and used according to PRISMA (Preferred Reporting Items for Systematic Reviews and Meta-Analyses) guidelines, and the process is shown in Fig. 1. Clinical information for statistical analysis, including tumor location, treatment modalities, extent of resection, and follow-up data, is detailed in Supplementary Tables 1-4. Two review authors independently assessed the bias in the included studies by considering the completeness of outcome data and selective outcome reporting. Disagreement between the review authors over the bias in particular studies was resolved by discussion, with involvement of a third review author when necessary. This systematic review has been registered (systematic review no.: CRD42018090878, crd.york.ac.uk/PROSPERO/).

\section{Surgical Management and Pathological Examination}

Several surgical approaches for resecting GCTs are detailed in Supplementary Table 3 and include the frontotemporal (transzygomatic) approach $(n=14,32.6 \%)$ for lesions involving the temporal squamous portion with or without invading the temporomandibular joint (TMJ), transsphenoidal endoscopic approach $(n=14,32.6 \%)$, far- 
TABLE 1. Patient demographics

\begin{tabular}{|c|c|c|c|}
\hline Variable & Present Series $(n=43) \dagger$ & Prior Studies $(n=90)$ & Overall $(n=133)$ \\
\hline \multicolumn{4}{|l|}{ Sex, n (\%) } \\
\hline Male & $28(65.1)$ & $48(53.3)$ & $76(57.1)$ \\
\hline Female & $15(34.9)$ & $42(46.7)$ & $57(42.9)$ \\
\hline \multicolumn{4}{|l|}{ Age, yrs } \\
\hline Median & 32.0 & 31.0 & 31.0 \\
\hline Mean \pm SD & $30.5 \pm 3.2$ & $32.7 \pm 3.6$ & $32.0 \pm 2.6$ \\
\hline \multicolumn{4}{|l|}{ Main complaint, $\mathrm{n}(\%)^{*}$} \\
\hline Visual field defect & $12(27.9)$ & $5(6.9)$ & $17(13.0)$ \\
\hline Hearing loss/tinnitus & $16(37.2)$ & $23(31.9)$ & $39(33.9)$ \\
\hline Diplopia & $5(11.6)$ & $6(8.3)$ & $11(9.6)$ \\
\hline Expanding mass/headache & $18(41.9)$ & $30(41.6)$ & $48(41.7)$ \\
\hline Oculomotor deficit & $7(16.3)$ & $4(5.6)$ & $11(9.6)$ \\
\hline \multicolumn{4}{|l|}{ Duration of Sx, mos $\ddagger$} \\
\hline Median (range) & $6.0(0.5-48.0)$ & $6.0(0.5-120)$ & $6.0(0.5-120)$ \\
\hline Mean \pm SD & $11.0 \pm 3.80$ & $15.0 \pm 6.0$ & $13.4 \pm 3.9$ \\
\hline \multicolumn{4}{|l|}{ Lesion location, $\mathrm{n}(\%)$} \\
\hline Temporal (TMJ) & $21(48.8)$ & $47(52.2)$ & $68(51.1)$ \\
\hline Sphenoid (ethmoid) & $17(39.5)$ & $30(33.3)$ & $47(35.3)$ \\
\hline Frontal & $1(2.3)$ & $4(4.4)$ & $5(3.8)$ \\
\hline Occipital (jugular foramen) & $4(9.3)$ & $9(10.0)$ & $13(9.8)$ \\
\hline \multicolumn{4}{|l|}{ Mean KPS score } \\
\hline Preop & $82.8 \pm 1.9$ & NA & NA \\
\hline Postop & $80.7 \pm 2.7$ & NA & NA \\
\hline Follow-up, n (\%)§ & $76.1 \pm 9.3$ & NA & NA \\
\hline \multicolumn{4}{|l|}{ Resection } \\
\hline GTR & $15(34.9)$ & $49(54.4)$ & $64(48.1)$ \\
\hline STR & $12(27.9)$ & $34(37.8)$ & $46(34.6)$ \\
\hline PR & $16(37.2)$ & $7(7.8)$ & $23(17.3)$ \\
\hline \multicolumn{4}{|l|}{ Follow-up duration, mos§ } \\
\hline Range & $3.4-177.0$ & $1.0-120.0$ & $1.0-177.0$ \\
\hline Mean \pm SD & $71.3 \pm 17.0$ & $31.5 \pm 6.4$ & $43.3 \pm 7.4$ \\
\hline Recurrence/progression, $\mathrm{n}(\%) \S$ & $12(31.6)$ & $17(18.9)$ & $29(22.7)$ \\
\hline Death during follow-up, $\mathrm{n}(\%) \S$ & $4(10.5)$ & $5(5.6)$ & $9(7.0)$ \\
\hline \multicolumn{4}{|c|}{$\begin{array}{l}\text { NA = not available; } S x=\text { symptoms. } \\
\text { *Eighteen patients in the prior studies did not provide main complaints. } \\
\dagger \text { Five patients in the present series were lost to follow-up but are included for patient demographics. } \\
\text { ‡ Data were not available for } 28 \text { patients in the prior studies. } \\
\S \text { The } 5 \text { patients in the present series who were lost to follow-up are excluded for this variable. }\end{array}$} \\
\hline
\end{tabular}

lateral approach $(n=4,9.3 \%)$, and anterior transpetrosal approach $(n=3,7.0 \%)$, among others.

Fresh paraffin-embedded tumor tissue was cut into 5- $\mu \mathrm{m}$ slices and stained with $\mathrm{H} \& \mathrm{E}$ (Fig. 2). Immunohistochemical staining was performed for CD34, CD68, S100, vimentin, lysozyme, epithelial membrane antigen (EMA), brachyury, and Ki-67/MIB-1. Diagnoses were established based on the typical histopathological characteristics of GCTs.

\section{Follow-Up and Statistical Analysis}

Clinical and radiographic follow-up was performed every 6 months within the first 2 years, then yearly thereaf- ter via outpatient follow-up or telephone interview. Mean values are presented with their SD. The primary outcome of GCTs was PFS, and its pertinent adverse factors were evaluated by univariate analysis (Table 2) and multivariate Cox regression analysis (Table 3 ). Due to the small number of deaths $(n=9,7.0 \%)$, the risk factors for OS were not performed. Secondary outcomes were PFS in subgroups with significant risk factors and their pertinent estimated mean PFS time (EMPT) calculated using the KaplanMeier method (log-rank test; Fig. 3). We also performed multivariate Cox regression analysis in the pooled cases $(\mathrm{n}=128)$. All analyses were performed using IBM SPSS (version 23.0, IBM Corp.) with significance set at $\mathrm{p}<0.05$. 


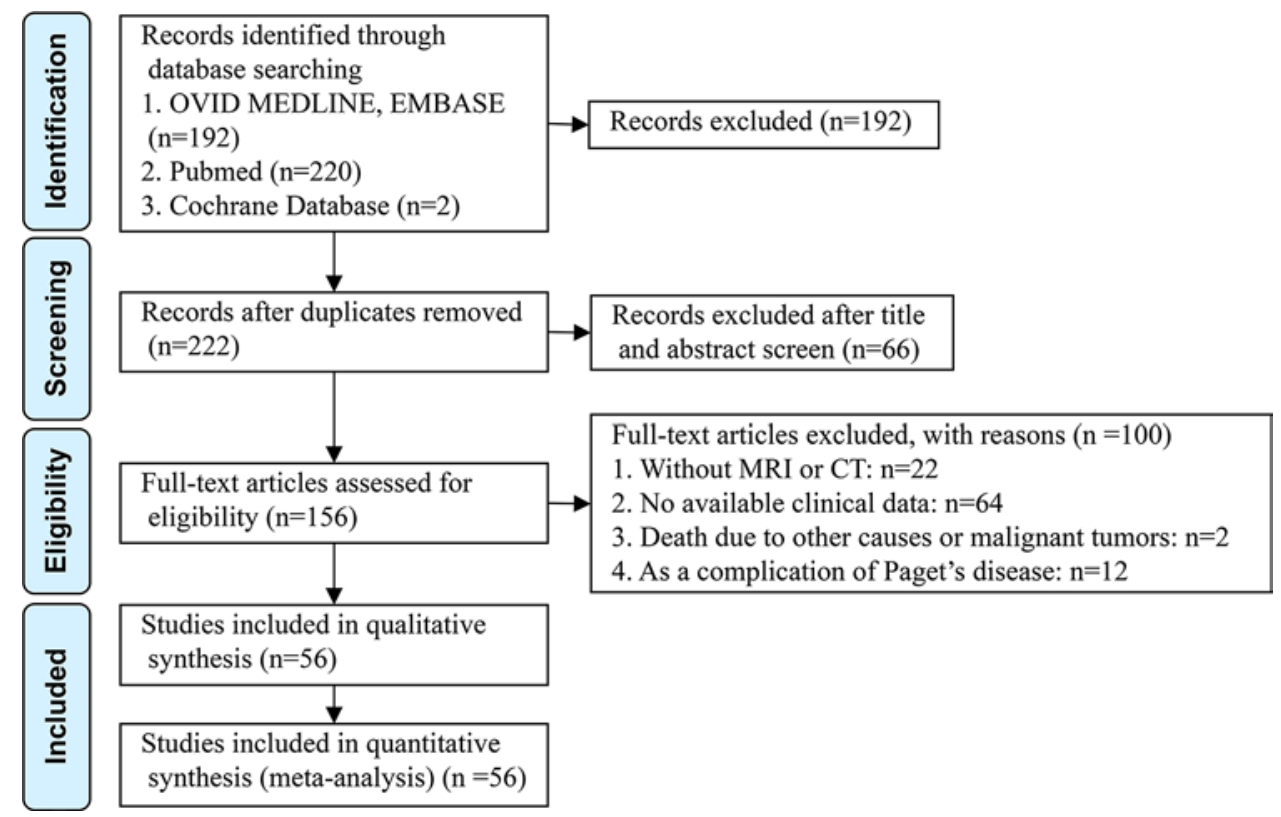

FIG. 1. PRISMA flow diagram showing the inclusion and exclusion process for the analysis. Figure is available in color online only.

\section{Results}

\section{Patient Demographics and Tumor Characteristics}

The present series included 28 males and 15 females with a median age of 32 years (range 3-55 years). The mean preoperative KPS score was $82.8 \pm 1.9$. Eight patients had undergone previous resection. The mean duration of symptoms was $11.0 \pm 3.8$ months (range $0.5-48.0$ months). The most common preoperative symptoms were expanding mass/headache $(\mathrm{n}=18,41.9 \%)$ and hearing loss/tinnitus ( $\mathrm{n}=16,37.2 \%$; Table 1$)$.

Forty-two $(97.7 \%)$ lesions originated from the skull base, and only $1(2.3 \%)$ was located in the frontal bone. Lesions were mainly located in temporal bone with or without involvement of the TMJ $(\mathrm{n}=21,48.8 \%)$ and sphenoid bone with or without extension into the ethmoid bone $(\mathrm{n}=17,39.5 \%)$. The mean tumor size was $4.1 \pm 0.3 \mathrm{~cm}$ (range 1.7-5.9 cm). The mean tumor volume was $44.3 \pm$ $9.3 \mathrm{~cm}^{3}$ (range $2.4-110.0 \mathrm{~cm}^{3}$ ).

\section{Radiographic Evaluation and Preoperative Diagnosis}

Both preoperative MR and CT images were obtained in all 43 patients. On CT scans, 42 (97.7\%) patients had osteolytic changes, and only 1 (2.3\%) demonstrated calcification. The most typical CT feature of GCTs was clearly demarcated and expansile osteolysis (Fig. 2). On T2-weighted MRI, a markedly hypointense region in the peritumoral area was noted in the majority of cases $(n=27,62.8 \%)$, which was more often found in GCTs involving temporal bone $(\mathrm{n}=17,81.0 \%)$ than GCTs involving sphenoid bone $(\mathrm{n}=6,35.3 \%) .{ }^{21}$ The lesion appeared mixed iso- and hypointense on T1-weighted $(\mathrm{n}=32,74.4 \%)$ and T2-weighted $(\mathrm{n}=23,53.5 \%)$ images, and exhibited heterogeneous enhancement on contrasted images $(\mathrm{n}=33,76.7 \%$; Fig. 4). Only $13(30.2 \%)$ cases were accurately diagnosed preoperatively. Fifteen (34.9\%) tumors had been diagnosed as chondroma, chondrosarcoma, or chordoma. Other tumors were diagnosed as aggressive pituitary adenoma $(\mathrm{n}=2$, $4.7 \%)$, jugular foramen schwannoma $(n=5,11.6 \%)$, aneurysmal bone cyst $(n=2,4.7 \%)$, malignant meningioma $(n=$ $4,9.3 \%)$, or osteolytic metastasis $(n=2,4.7 \%)$.

\section{Surgical Findings}

Treatment was tailored to the individual patient in all cases. Intraoperatively, all tumors were extradural with close adhesion to the dura mater and destruction to surrounding bones. Tumor consistencies were soft/crisp in 9 (20.9\%), tenacious in $26(60.5 \%)$, and hard in $8(18.6 \%)$ cases. The blood supply was abundant in 39 cases $(90.7 \%)$ and moderate in 4 cases $(9.3 \%)$. The surgical plane was poorly defined in 34 cases (79.1\%) and well distinguishable in 9 cases (20.9\%). Blood loss during surgery ranged from 100.0 to $5200.0 \mathrm{ml}$, with a mean volume of $1667.4 \pm$ $388.5 \mathrm{ml}$.

\section{Surgical Outcomes}

GTR, STR, and PR were achieved in 15 (34.9\%), 12 (27.9\%), and 16 (37.2\%) patients, respectively. Severe surgical complications directly leading to mortality or permanently worsened neurological status were not observed. Four patients experienced other complications, including pneumonia $(\mathrm{n}=1,2.3 \%)$, intracranial infection $(\mathrm{n}=1$, $2.3 \%$ ), and CSF leak $(\mathrm{n}=2,4.7 \%)$ (Supplementary Table 3). At discharge, the mean KPS score was $80.7 \pm 2.7$ (range 50-100). Postoperative adjuvant radiotherapy was administered to 15 (39.5\%) patients, among whom $10(66.7 \%)$ patients received intensity-modulated radiotherapy (IMRT), 3 patients (20.0\%) received Gamma Knife radiosurgery (GKRS; Leksell Gamma Knife C), and 2 patients (13.3\%) received stereotactic radiosurgery. The total dose of the fractionated local irradiation ranged from 40 to $64 \mathrm{~Gy}$ 
TABLE 2. Overall cohort demographics and baseline of the subset data based on tumor progression

\begin{tabular}{|c|c|c|c|c|}
\hline \multirow[b]{2}{*}{ Variable } & \multirow[b]{2}{*}{ Overall $(n=43)$} & \multicolumn{2}{|c|}{ Tumor Progression* } & \multirow[b]{2}{*}{$p$ Value } \\
\hline & & Yes $(n=12)$ & No $(n=26)$ & \\
\hline Female sex, $\mathrm{n}(\%)$ & $15(34.9)$ & $5(41.7)$ & $7(58.3)$ & $0.460 \dagger$ \\
\hline Mean age, yrs & $30.5 \pm 3.2$ & $30 \pm 5.0$ & $28.9 \pm 4.5$ & $0.775 \ddagger$ \\
\hline Mean preop KPS score & $82.8 \pm 1.9$ & $79.2 \pm 4.6$ & $84.2 \pm 2.0$ & $0.087 \S$ \\
\hline Mean duration of Sx, mos & $11.0 \pm 3.8$ & $7.6 \pm 3.8$ & $12.1 \pm 5.1$ & $0.816 \S$ \\
\hline Mean tumor size, $\mathrm{cm}$ & $4.1 \pm 0.3$ & $4.0 \pm 0.8$ & $4.2 \pm 0.4$ & $0.531 \ddagger$ \\
\hline History of resection, $\mathrm{n}(\%)$ & $8(18.6)$ & $3(25.0)$ & $3(11.5)$ & $0.357 \dagger$ \\
\hline Extent of resection, $\mathrm{n}(\%)$ & & & & $<0.001 \dagger$ \\
\hline GTR & $15(34.9)$ & 0 & $14(53.8)$ & \\
\hline STR & $12(27.9)$ & $2(16.7)$ & $7(26.9)$ & \\
\hline PR/biopsy & $16(37.2)$ & $10(83.3)$ & $5(19.3)$ & \\
\hline Image stage, n (\%) & & & & $0.047 \dagger$ \\
\hline I & $11(25.6)$ & $1(8.3)$ & $9(34.6)$ & \\
\hline II & $16(37.2)$ & $3(25.0)$ & $10(38.5)$ & \\
\hline III & $16(37.2)$ & $8(66.7)$ & $7(26.9)$ & \\
\hline Pathology, n (\%) & & & & $0.020 \dagger$ \\
\hline Ki- $67<10 \%$ & $23(53.5)$ & $3(25.0)$ & $17(65.4)$ & \\
\hline $\mathrm{Ki}-67 \geq 10 \%$ & $20(46.5)$ & $9(75.0)$ & $9(34.6)$ & \\
\hline Postop radiotherapy, $\mathrm{n}(\%)$ & & & & $0.148 \dagger$ \\
\hline Yes & $15(32.6)$ & $3(25.0)$ & $12(46.2)$ & \\
\hline No & $29(67.4)$ & $9(75.0)$ & $14(53.8)$ & \\
\hline
\end{tabular}

Boldface type indicates statistical significance.

* Five patients lost to follow-up were excluded.

† Chi-square test.

$\ddagger$ Independent samples t-test.

$\S$ Mann-Whitney test.

with mean and median doses of $54.7 \pm 4.1 \mathrm{~Gy}$ and $56.8 \mathrm{~Gy}$ (single dose 1.8-2 Gy and 20-33 fractions), respectively. GKRS was used in 3 patients (mean central dose $31.0 \mathrm{~Gy}$ [range 29.0-33.0 Gy] and mean marginal dose 13.0 Gy [range 10.0-15.0 Gy]; Supplementary Table 2).

Five patients were lost to follow-up. After a mean follow-up duration of $71.3 \pm 17.0$ months (range 3.4-177.0 months), 12 patients (31.6\%) experienced recurrence with a median PFS of 9.9 months (range 3.4-65.9 months). One patient underwent a second operation followed by radiotherapy, and 3 patients received radiotherapy alone; all were alive with disease. One patient received a second operation alone but unfortunately died even after salvage treatment. Other patients $(n=7)$ refused to receive any treatment after tumor progression. Overall, 4 patients with recurrence died of disease and had a median survival time of 35.1 months (range 13.3-61.3 months). At the recent follow-up evaluation, the mean KPS score was $76.1 \pm 9.3$ (range 0-100).

\section{Histological Examination}

All GCTs in our report exhibited similar histological features. $\mathrm{H} \& \mathrm{E}$ staining showed that the tumors typically had numerous multinucleated giant cells containing as many as $50-70$ nuclei, lacked atypical nuclei, and were scattered in a background of uniform mononuclear cells. Numerous ovoid- to spindle-shaped stromal cells with eo- sinophilic cytoplasm were also present, as well as several foci of hemosiderin pigment deposition and no areas of necrosis. The results of immunohistochemical analysis revealed the following: there were $43(100 \%), 36(83.7 \%)$, and 39 (90.7\%) tumors positive for CD68, lysozyme, and vimentin, respectively; 41 (95.3\%) tumors negative for S100; 1 of $13(7.7 \%)$ tumors suspiciously positive for brachyury; and 4 tumors negative for EMA. Based on the Ki-67 value of $10 \%$ as a cutoff, there were $20(46.5 \%)$ malignant GCTs.

\section{Individual Patient Data of Previous Cases}

Ninety cases of GCTs were identified (Supplementary Table 4) in 48 males and 42 females with a mean and median age of $32.7 \pm 3.6$ years and 31.0 years, respectively. The most common preoperative symptoms were expanding mass/headache $(\mathrm{n}=30,41.6 \%)$ and hearing loss/tinnitus $(\mathrm{n}=23,31.9 \%)$. The duration of symptoms ranged from 0.5 to 120 months (median 6.0 months). Lesions predominantly involved the temporal bone with or without involvement of the TMJ $(\mathrm{n}=47,52.2 \%)$ followed by the sphenoid bone with or without involvement of the ethmoid bone $(\mathrm{n}=30,33.3 \%)$, occipital bone/jugular foramen $(\mathrm{n}=$ $9,10 \%)$, and frontal bone ( $\mathrm{n}=4,4.4 \%$; Table 1$)$.

GTR, STR, and PR were achieved in 49 (54.4\%), 34 (37.8\%), and 7 (7.8\%) cases, respectively. Radiotherapy was administered to 33 patients (36.7\%; available radiotherapy doses were not provided for 14 cases), with a mean 
TABLE 3. Multivariate Cox regression for risk factors predicting PFS for our series and pooled cases

\begin{tabular}{|c|c|c|c|c|c|c|c|c|c|c|}
\hline \multirow[b]{3}{*}{ Risk Factor } & \multicolumn{5}{|c|}{ Our Series } & \multicolumn{5}{|c|}{ Pooled Cases } \\
\hline & \multirow{2}{*}{$\begin{array}{c}\text { No. of } \\
\text { Recurrences }\end{array}$} & \multicolumn{2}{|c|}{ PFS } & \multicolumn{2}{|c|}{ PFS for Our Series* } & \multirow{2}{*}{$\begin{array}{c}\text { No. of } \\
\text { Recurrences }\end{array}$} & \multicolumn{2}{|c|}{ PFS } & \multicolumn{2}{|c|}{ PFS in Pooled Cases* } \\
\hline & & $1-Y r$ & $5-Y r$ & $\mathrm{HR}(95 \% \mathrm{Cl})$ & $p$ Value & & $1-Y r$ & $5-Y r$ & $\operatorname{HR}(95 \% \mathrm{Cl})$ & $p$ Value \\
\hline Overall & $12(31.6)$ & 81.6 & 68.6 & & & $29(22.7)$ & 88.8 & 69.6 & & \\
\hline Sex & & & & $1.790(0.341-9.385)$ & 0.491 & & & & $1.913(0.881-4.156)$ & 0.101 \\
\hline Male & $7(58.3)$ & 88.5 & 74.4 & & & $16(55.2)$ & 89.0 & 72.8 & & \\
\hline Female & $5(41.7)$ & 66.7 & 58.3 & & & $13(44.8)$ & 88.6 & 65.5 & & \\
\hline Extent of resection & & & & 7.909 (2.296-27.247) & 0.001 & & & & 4.792 (2.909-7.893) & $<0.001$ \\
\hline GTR & 0 & 100 & 100 & & & $3(10.3)$ & 100 & 87.0 & & \\
\hline STR & $2(16.7)$ & 77.8 & 77.8 & & & $12(41.4)$ & 88.1 & 65.1 & & \\
\hline PR & $10(83.3)$ & 66.7 & 36.0 & & & $14(48.3)$ & 59.1 & 34.8 & & \\
\hline $\begin{array}{l}\text { Preop KPS score, per } \\
\text { 10-point increase }\end{array}$ & & & & $0.969(0.873-1.075)$ & 0.549 & & & & & \\
\hline Pathology & & & & $7.816(1.584-38.575)$ & 0.012 & & & & & \\
\hline Ki- $67<10 \%$ & $3(25.0)$ & 100 & 85.9 & & & & & & & \\
\hline Ki- $67 \geq 10 \%$ & $9(75.0)$ & 61.1 & 50.0 & & & & & & & \\
\hline Postop radiotherapy & & & & $0.114(0.023-0.568)$ & 0.008 & & & & $0.165(0.065-0.423)$ & $<0.001$ \\
\hline Yes & $3(25.0)$ & 92.9 & 77.9 & & & $6(20.7)$ & 95.7 & 80.5 & & \\
\hline No & $9(75.0)$ & 75.0 & 63.0 & & & $23(79.3)$ & 84.7 & 62.3 & & \\
\hline Image stage & & & & $1.403(0.295-6.667)$ & 0.670 & & & & & \\
\hline 1 & $1(8.3)$ & 100 & 83.3 & & & & & & & \\
\hline II & $3(25.0)$ & 92.3 & 84.6 & & & & & & & \\
\hline III & $8(66.7)$ & 60.0 & 45.7 & & & & & & & \\
\hline
\end{tabular}

Boldface type indicates statistical significance.

* Backward stepwise (likelihood ratio).

and median dose of $47.1 \pm 5.6$ and 46.8 Gy (range 18.4$76.0 \mathrm{~Gy}$ ), respectively. The detailed treatment modalities are listed in Supplementary Tables 2 and 4. After a mean follow-up duration of $31.5 \pm 6.4$ months (range 1.0-120.0 months), 17 patients experienced recurrence with a median PFS time of 12.0 months (range 1.0-50.0 months), and 5 patients died with a median OS of 19.0 months (range 1.0-48.0 months).

\section{Factors Affecting PFS}

The factors associated with PFS in our cohort as determined by univariate analysis (Ki-67, image stage, postoperative radiotherapy, and extent of resection; Table 2) were included in the multivariate analysis. The following factors remained statistically significant: PR (HR 7.909, 95\% CI 2.296-27.247, p = 0.001; Fig. 3A), Ki-67 $\geq 10 \%$ (HR 7.816, $95 \%$ CI 1.584-38.575, $\mathrm{p}=0.012$ [multivariate Cox regression]; Fig. 3B), and radiation therapy (HR 0.114, 95\% CI $0.023-0.568, p=0.008$ [multivariate Cox regression]; Fig. $3 \mathrm{C})$. The increased dose of radiation ( $\geq 45 \mathrm{~Gy}$ ) was significantly associated with better PFS (Fig. 3D). However, image stage III ( $p=0.670$; Fig. 3E), pre-KPS ( $p=0.549)$, and female sex $(p=0.491)$ were no longer significant (Table 3$)$.

In the pooled cohort $(\mathrm{n}=128$, not including the 5 patients lost to follow-up), 29 patients (22.7\%) experienced recurrence, with actuarial PFS rates at 1 and 5 years of $88.8 \%$ and $69.6 \%$, respectively, and actuarial OS rates at 1 and 5 years of $98.4 \%$ and $89.2 \%$, respectively (Fig. 3F).
Multivariate analysis identified PR (HR 4.792, 95\% CI 2.909-7.893, p < 0.001; Fig. 3G) and no radiotherapy (HR $0.165,95 \%$ CI $0.065-0.423, \mathrm{p}<0.001$ [multivariate Cox regression]; Fig. $3 \mathrm{H}$ ) as risk factors for poor PFS. Female sex $(\mathrm{p}=0.101)$ and dose of radiation $(\mathrm{p}=0.124 ;$ Fig. $3 \mathrm{I})$ were insignificant (Table 3). Additionally, the overall different PFS rates among patients stratified by 4 treatment protocols were statistically significant $(\mathrm{p}<0.001$; Fig. 3J and Table 4), with a 5-year PFS of $100 \%$ for GTR plus radiation therapy, followed by GTR alone (85.8\%), non-GTR plus radiation therapy (77.6\%), and non-GTR alone (20.8\%).

\section{Discussion}

Intracranial GCTs are extremely rare, and most have been presented as case reports. Due to the paucity of data regarding GCTs, no specific treatment modalities are proposed for GCTs, and their prognosis has been generally described as dismal with a propensity for recurrence. Based on our series and prior studies, we verified adverse factors for PFS and significantly different PFS rates following various treatment modalities.

\section{Clinical Symptoms, Radiological Features, and Differential Diagnosis}

The most common initial symptom was expanding mass/intermittent headache $(n=48,41.7 \%)$; the duration of symptoms varied extensively (Table 1 ). When the temporal bone lesions invaded posteriorly, patients often presented 
TABLE 4. PFS of different treatment protocols

\begin{tabular}{|c|c|c|c|c|c|c|}
\hline \multirow[b]{2}{*}{ Treatment } & \multirow[b]{2}{*}{ No. of Pts } & \multirow[b]{2}{*}{ No. of Relapses } & \multicolumn{2}{|c|}{ PFS } & \multirow[b]{2}{*}{$\operatorname{HR}(95 \% \mathrm{Cl})^{*}$} & \multirow[b]{2}{*}{$\mathrm{p}$ Value } \\
\hline & & & $1-Y r$ & $5-Y r$ & & \\
\hline Overall & 128 & $29(22.7)$ & 88.8 & 69.6 & $2.673(1.766-4.047)$ & $<0.001$ \\
\hline GTR + RT & 9 & 0 & 100 & 100 & NA & 0.985 \\
\hline GTR alone & 54 & $3(10.3)$ & 100 & 85.8 & Reference $†$ & \\
\hline Non-GTR + RT & 38 & $6(15.8)$ & 94.7 & 77.6 & $2.706(0.675-10.841)$ & 0.160 \\
\hline Non-GTR alone & 27 & $20(69.0)$ & 55.0 & 20.8 & $22.365(6.555-76.311)$ & $<0.001$ \\
\hline
\end{tabular}

Pts = patients; $\mathrm{RT}=$ radiotherapy

Boldface type indicates statistical significance. Due to the small sample size, the treatment protocols were based on our institution's cases plus the cases reported before. The overall cohort was classified into 4 groups according to extent of resection (GTR or not) and adjuvant treatment (radiotherapy or not).

${ }^{*}$ Cox regression method.

$\dagger$ Because all cases were censored in the subgroup of GTR plus radiotherapy, the comparison between this subgroup (if it was designated as the reference) and any other subgroup could not be computed. Therefore, we selected the subgroup of GTR alone as the reference (dummy variable).

with conductive hearing loss and/or a mass in the middle ear. Lesions involving the petrous apex often presented with vertigo and/or sensorineural hearing loss. ${ }^{17,44}$ Sphenoid bone GCTs were usually detected due to mass effect. When the lesion invaded the optic canal and cavernous sinuses, visual field deficits and third and sixth cranial nerve palsies often developed. ${ }^{42}$

In our cases, tumors as osteolytic pathologies usually destroyed surrounding bone structures, causing a bone-deficient area. Although fairly well circumscribed, some cystic changes, ballooning, and perforation of the bony cortex may be noted. The area of destruction has a "soap bubble" appearance on CT scans. ${ }^{18,24,38}$ The most typical presentation on MRI was remarkable hypointensity surrounding the lesions on T2-weighted images (62.8\%), mixed iso- and hypointensity on T1-weighted (74.7\%) and T2weighted $(53.5 \%)$ images, and usually heterogeneous enhancement with the administration of gadolinium $(76.7 \%$; Supplementary Table 1). The remarkable hypointensity was associated with massive hemosiderin deposition or callus formation related to the healing of a pathological fracture; in our series, this feature was more frequently seen in temporal bone $(81.0 \%){ }^{21}$
Differential diagnoses based on imaging findings included chondroma, chordoma, chondrosarcoma, aggressive pituitary adenomas, aneurysmal bone cyst, giant cell reparative granuloma (GCRG), metastatic carcinoma, and brown tumor. When encountering an osteolytic mass of the sphenoid body, the differential diagnosis should include the aforementioned lesions. Calcification and hyperintensity on T2-weighted images are generally not features of GCTs and would thus favor a diagnosis of chordoma, chondroma, or chondrosarcoma. ${ }^{21}$ The most common MRI presentation of an aggressive pituitary adenoma was isointensity on T1-weighted images, slight hyperintensity on T2-weighted images, and homogeneous enhancement on contrasted MRI, which helped to distinguish this entity from GCTs. GCRG was a reactive inflammatory process related to trauma and interosseous hemorrhage that predominantly involved the mandible. At pathologic analysis, GCRG had a prominent fibroblastic stroma and small giant cells in granuloma-like arrangements around the foci of the hemorrhage. ${ }^{4,26,31}$ Brown tumor associated with hyperparathyroidism was a nonneoplastic focal bone lesion that mostly involved the craniofacial bones, which could be differentiated because of metabolic abnormalities.,31

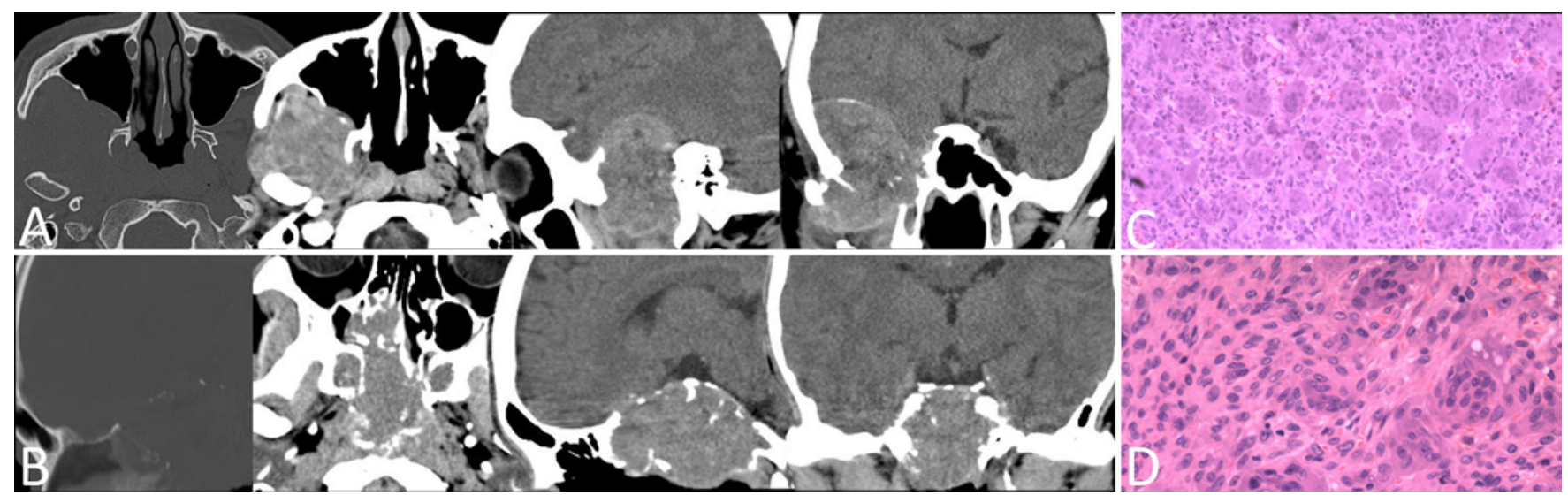

FIG. 2. A and B: Preoperative CT scans showing a lesion located in the temporal bone expanding into the TMJ (A) and a sphenoid lesion involving the ethmoid bone (B) that presented as a sharply circumscribed, expansile, lytic bone lesion. C and D: H \& E staining of GCTs revealing numerous multinucleated giant cells that lack atypical nuclei, scattered in a background of uniform mononuclear cells. Original magnification $\times 100$ (C); ×400 (D). Figure is available in color online only. 


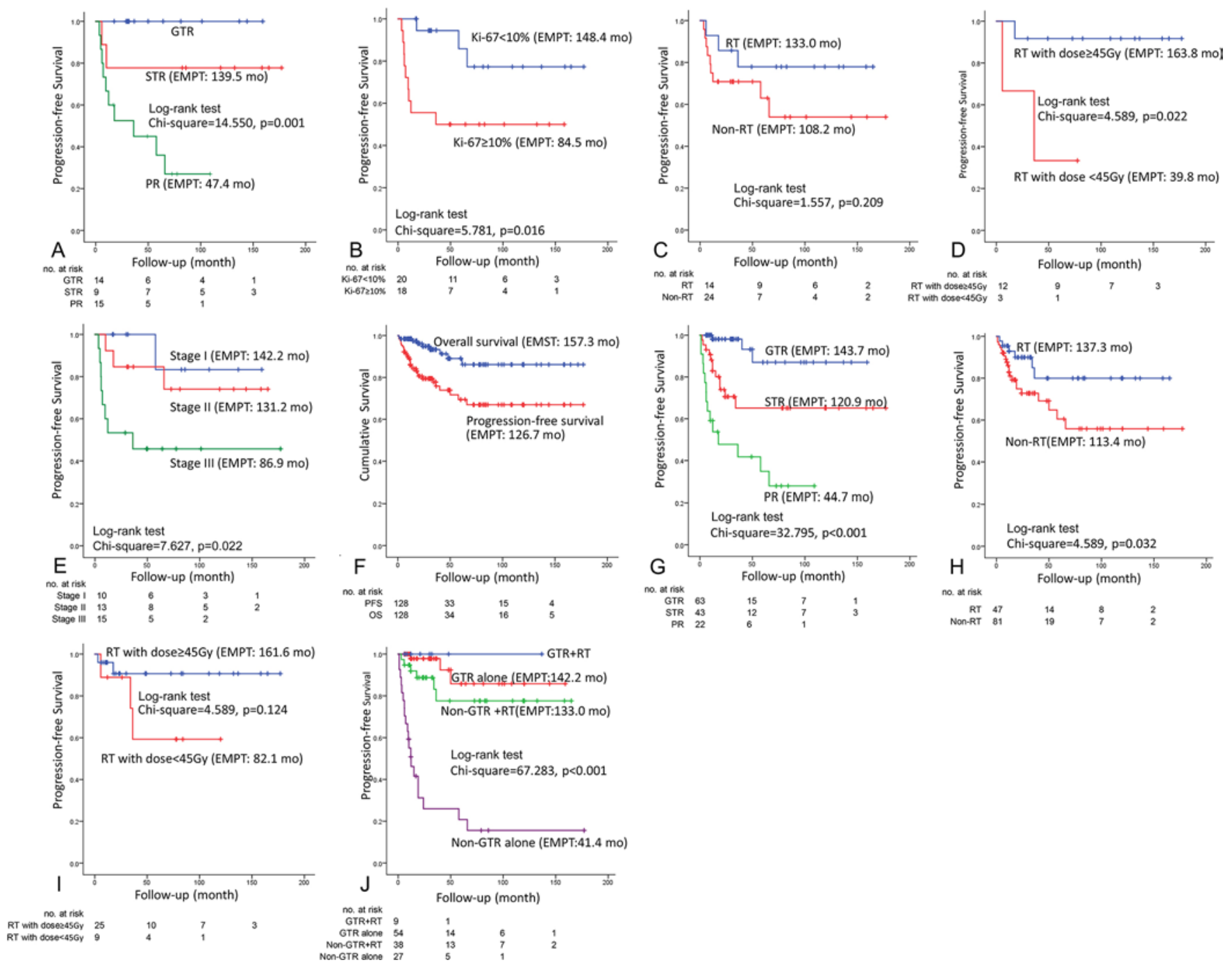

FIG. 3. Kaplan-Meier curve analysis (log-rank test) showing the different PFS rates among GTR, STR, and PR (A); between Ki-67 $<10 \%$ and Ki-67 $\geq 10 \%$ (B); between radiotherapy (RT) and non-RT (C); between RT with dose $\geq 45$ Gy and < 45 Gy (D); and among image stages I, II, and III (E). Kaplan-Meier curve (log-rank test) showing OS and PFS of the pooled cohort (F); the different PFS times among GTR, STR, and PR (G); between RT and non-RT (H); between RT with a total dose $\geq 45$ Gy and $<45$ Gy (I); and the different PFS rates of these 4 treatment protocols (J). Patients with GTR plus RT, GTR alone, or non-GTR plus RT had significantly better PFS than patients with non-GTR alone. Figure is available in color online only.

Aneurysmal bone cyst could be in the differential diagnosis by pathology that presented with multiple cavernous blood-filled spaces alternating with solid areas containing fibrous elements and numerous giant cells. ${ }^{2}$

\section{Histological Characteristic of GCTs}

Because of different treatment protocols and outcomes between osteogenesis tumors, we should differentiate GCTs from other osteolytic lesions. The typical manifestation on $\mathrm{H} \& \mathrm{E}$ staining was multinucleated giant cells scattered in a background of uniform mononuclear cells, and it was not uncommon that a giant cell contained 50-70 nuclei. GCTs rarely had abundant spindle cells or numerous hemosiderin-laden macrophages, which lacked nuclear atypia and were more cellular than low-grade sarcomas. GCTs were positive for CD68, vimentin, and lysozyme but negative for S100, EMA, and brachyury, which facilitated distinguishing the GCTs from osteosarcoma and chondroblastoma. ${ }^{8,10,17}$

\section{Progression-Free Survival and Risk Factors}

The PFS varied among studies largely depending on treatment modalities. Zhang et al..$^{44}$ found non-GTR and no radiotherapy as risk factors for PFS, and patients with STR had significantly better survival if postoperative radiotherapy was delivered. The upgraded image stage suggesting aggressive growth was significant on univariate analysis (Fig. 3E), but insignificant in the multivariate model. Our multivariate analysis revealed Ki-67 $\geq 10 \%$, decreased extent of resection, and no radiotherapy as independent adverse factors for poor PFS (Table 3). With regard to radiation dose, the PFS in the subgroup that re- 

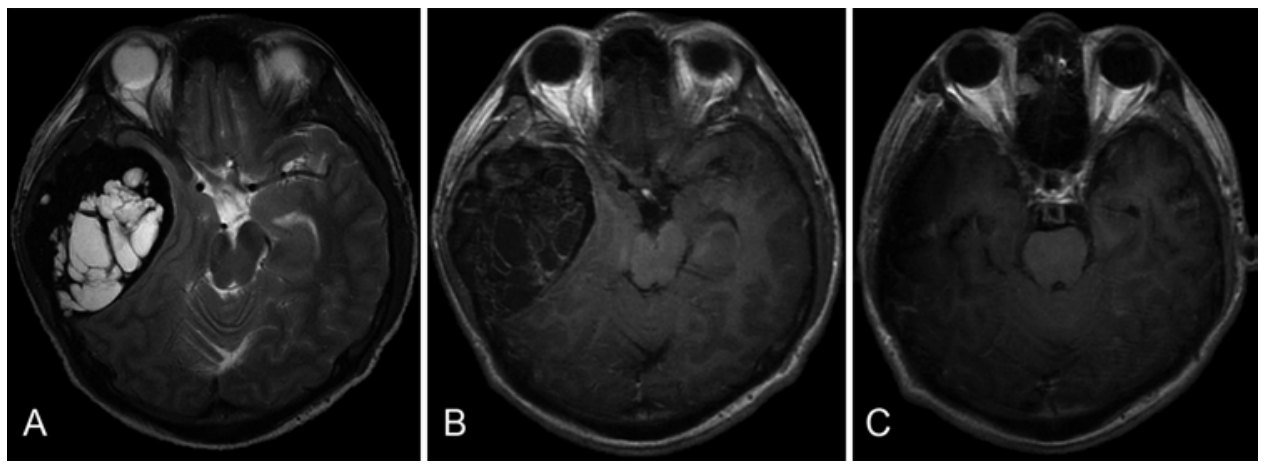

FIG. 4. A case of GCT in a 28-year-old man whose main complaint was tinnitus accompanying a headache for 12 months. Preoperative contrast MRI scans showing a lesion located in the temporal bone expanding into the TMJ: mixed iso- and hyperintensity accompanying extremely hypointense peripheral lesion on T2-weighted image $(\mathbf{A})$ and heterogeneous enhancement on contrasted MR image (B). After GTR, there was no additional treatment for him. Contrasted MRI scans (C) showed complete resection without recurrence after 144 months.

ceived doses $\geq 45$ Gy (91.7\% at 5 years) was significantly better than that in the subgroup with doses $<45$ Gy $(33.3 \%$ at 5 years; Fig. 3D). In the pooled analysis, resection and postoperative radiation therapy remained significant, but the dose of radiation was insignificant, which might be due to small sample size.

\section{Proposed Treatment Algorithm}

All previous reports included in our study advocated GTR as the optimal therapy, but the value of non-GTR plus postoperative radiotherapy has been controversial over the decades. Malignant transformation as a result of external-beam radiation therapy using orthovoltage treatment had been reported, ranging from $7 \%$ to $29 \% .{ }^{34}$ Due to the risk of malignant transformation, some authors prefer reoperation rather than postoperative radiation therapy. ${ }^{11,39}$ However, in our series, no malignant transformation after radiation therapy was observed; in contrast, it was impossible to determine whether a malignant transformation was the natural course of the untreated disease. ${ }^{43}$ In the past 4 decades, radiotherapy using newly developed megavoltage equipment has been utilized as adjuvant treatment for GCTs and has resulted in excellent local control with minor and tolerable complications. ${ }^{25,38}$ A growing number of authors believe that GCTs are radiosensitive, and radiotherapy played an essential role in recurrence control..$^{3,6,8,9,17,27,29,33,35}$ Malone et al. ${ }^{25}$ reported that local control was achieved in 19 of 21 patients with radiotherapy and recommended the modality as an effective option if surgery was impossible or would result in significant morbidity. Therefore, postoperative radiation therapy was recommended to patients with at least one of the following entities: 1) malignant pathology with a Ki-67 index $\geq 10 \%$ regardless of extent of resection; 2) residual tumors regardless of Ki-67 index; and 3) recurrent GCT. Postoperative radiation therapy was not required immediately in patients with both GTR and Ki-67 index < 10\%. Notwithstanding, scheduled MRI reexamination every 3-6 months within the first 5 years was mandatory.

There is a considerable variation in total dose and fractionation in the literature. Malone et al. ${ }^{25}$ reported radiotherapy with a dose of $35 \mathrm{~Gy}$ in 15 fractions as a safe and effective treatment regimen. Feigenberg et al. ${ }^{12}$ found a significant increased local control rate of $86 \%$ with doses above 40 Gy compared with $67 \%$ with lower doses. Geissinger et al ${ }^{14}$ found that sarcomatous transformation was below $1 \%$ after application of $50 \mathrm{~Gy}$. Roeder et al. ${ }^{35}$ questioned whether dose escalation exceeding doses of 45 Gy increased local control. In the pooled cohort, the significantly different 5-year PFS rates among these 4 treatment modalities (Fig. 3J) supported an optimal protocol consisting of GTR and radiotherapy. It is not contradictory that the statistical difference was insignificant between subgroups (GTR alone vs non-GTR plus radiotherapy, $p$ $=0.160$ ) but is significant within the whole cohort when stratified by treatment protocols (Fig. 3J) that implied a significant tendency of stepwise poor PFS if patients did not receive GTR or radiation. These results provided somewhat credible evidence for clinicians and patients when deciding treatment modality. Additionally, the significant importance of radiotherapy dose $\geq 45$ Gy also played an essential role in prolonging PFS. ${ }^{36}$ Therefore, we advised using stereotactic radiosurgery or IMRT with a total dose $\geq 45 \mathrm{~Gy}$ to control the non-GTR lesions. Kim et al. ${ }^{22}$ reported on a patient who received GKRS after 10 months, and the tumor remained unchanged in size. However, they suggested that GKRS could be an effective treatment option for the management of intracranial GCT recurrence after previous surgery and radiation therapy. Three of our patients received GKRS after non-GTR, and 2 patients had local control but 1 recurrence after 18 months. IMRT with a dose of 57.6 Gy was administered for this recurrence, and after 24 months following IMRT, the lesions shrank. Therefore, whether GKRS was advised for GCTs was still controversial, and more studies are necessary to verify the effect of GKRS.

For tumor recurrence, there were several reports of favorable outcomes with chemotherapy. Yamamoto et al. ${ }^{43}$ suggested that Adriamycin was effective in controlling local disease in surgically inaccessible and radioresistant GCTs, as well as in remnant or recurrent tumors. Other authors concluded that inhibition of receptor activator of nuclear factor kappa- $\beta$ ligand (RANKL) and bisphosphonate therapy might eliminate giant cells; this approach might 
be useful for recurrent or unresectable skull GCTs. ${ }^{13,16,30,40}$ A phase II trial of RANKL by Branstetter et al. ${ }^{5}$ demonstrated a decrease of $\geq 90 \%$ giant cells and a reduction in stromal cells. In summary, we advised reoperation plus radiotherapy (dose $\geq 45 \mathrm{~Gy}$ ) as an optimal choice for radiosensitive and resectable recurrent lesions and chemical therapy with Adriamycin/denosumab/bisphosphonate as salvage treatment for unresectable and radioresistant lesions; however, future studies are still needed.

\section{Limitations of the Present Study}

First, the main limitations were the retrospective nature, limited sample size, and literature spanning the course of 35 years. Second, the radiotherapy method and dose were not available in some prior cases. Third, the effect of chemotherapy was beyond the scope of the present study. Due to the rarity of GCTs, there was a lack of randomized data, and potential bias (selection bias) might exist in the pooled data analysis. Because in most subgroups more than half of the patients were censored and some patients stayed PFS much longer, the estimated median survival time could not be calculated. Consequently, the estimated mean survival time was used. Theoretically, the median could provide a more appropriate estimate for a typical survival time than the mean, and we also found that the estimated mean survival time grossly overestimated the PFS of GCTs and was not appropriate to extrapolate beyond the extent of the actual data. Meanwhile, in 2 top curves without recurrence (Fig. 3A and J) it was not possible to calculate the EMPT. Nevertheless, the different PFS rates between subgroups were determined by Cox regression rather than depending on EMPT. A multicenter randomized controlled study based on a large cohort was necessary to determine an optimal treatment protocol.

\section{Conclusions}

Intracranial GCTs are rare neoplasms with a slight male predilection. GCTs predominantly involve temporal bone with typical radiological features. GTR and radiotherapy were independent favorable factors for PFS. Based on these favorable factors, GTR with or without radiotherapy, followed by non-GTR plus radiotherapy (dose $\geq$ $45 \mathrm{~Gy}$ ), if tolerable, is advocated as the optimal treatment for primary intracranial GCTs. Future studies with larger cohorts are necessary to verify our findings.

\section{Acknowledgments}

We thank our senior statistician Dr. Dan Xiao from Department of Epidemiology, China National Clinical Research Center for Neurological Disease, Beijing, and Dr. Wei Feng from Department of Epidemiology and Health Statistics, School of Public Health, Capital Medical University, Beijing, for supervising and improving the confidence of statistical analysis.

\section{References}

1. Antal I, Sápi Z, Szendröi M: The prognostic significance of DNA cytophotometry and proliferation index (Ki-67) in giant cell tumors of bone. Int Orthop 23:315-319, 1999

2. Bibas-Bonet H, Fauze RA, Lavado MG, Páez RO, Nieman $\mathrm{J}$ : Garcin syndrome resulting from a giant cell tumor of the skull base in a child. Pediatr Neurol 28:392-395, 2003
3. Billingsley JT, Wiet RM, Petruzzelli GJ, Byrne R: A locally invasive giant cell tumor of the skull base: case report. J Neurol Surg Rep 75:e175-e179, 2014

4. Borges BB, Fornazieri MA, Bezerra AP, Martins LA, Pinna Fde R, Voegels RL: Giant cell bone lesions in the craniofacial region: a diagnostic and therapeutic challenge. Int Forum Allergy Rhinol 2:501-506, 2012

5. Branstetter DG, Nelson SD, Manivel JC, Blay JY, Chawla $\mathrm{S}$, Thomas DM, et al: Denosumab induces tumor reduction and bone formation in patients with giant-cell tumor of bone. Clin Cancer Res 18:4415-4424, 2012

6. Byun JH, Park KB, Ko JS, Ahn SK: Giant cell tumor of infratemporal fossa and mandibular condyle: a case report. J Int Adv Otol 11:88-91, 2015

7. Carmody RF, Rickles DJ, Johnson SF: Giant cell tumor of the sphenoid bone. J Comput Assist Tomogr 7:370-373, 1983

8. Chiarini L, Figurelli S, Ghidini A, Nocini PF, Procacci P, Rubini C, et al: An unusual case of giant cell tumour involving the middle cranial fossa, originating from soft tissues of the temporomandibular joint. Acta Neurochir (Wien) 151:1685-1687, 2009

9. do Amaral CM, Julio GL, Cardoso LA, Bueno MA: Craniofacial treatment of giant-cell tumors of the sphenoid bone. $\mathbf{J}$ Craniofac Surg 5:254-256, 1994

10. Elder JB, Berry C, Gonzalez-Gomez I, Kreger MD, McComb JG: Giant cell tumor of the skull in pediatric patients. Report of two cases. J Neurosurg 107 (1 Suppl):69-74, 2007

11. Epstein N, Whelan M, Reed D, Aleksic S: Giant cell tumor of the skull: a report of two cases. Neurosurgery 11:263-267, 1982

12. Feigenberg SJ, Marcus RB Jr, Zlotecki RA, Scarborough MT, Berrey BH, Enneking WF: Radiation therapy for giant cell tumors of bone. Clin Orthop Relat Res (411):207-216, 2003

13. Freeman JL, Oushy S, Schowinsky J, Sillau S, Youssef AS: Invasive giant cell tumor of the lateral skull base: a systematic review, meta-analysis, and case illustration. World Neurosurg 96:47-57, 2016

14. Geissinger JD, Siqueira EB, Ross ER: Giant cell tumors of the sphenoid bone. J Neurosurg 32:665-670, 1970

15. Gupta R, Mohindra S, Mahore A, Mathuriya SN, Radotra BD: Giant cell tumour of the clivus. Br J Neurosurg 22:447-449, 2008

16. Inoue A, Ohnishi T, Kohno S, Nishikawa M, Nishida N, Ohue $\mathrm{S}$ : Role of denosumab in endoscopic endonasal treatment for juvenile clival giant cell tumor: a case report and review of the literature. World Neurosurg 91:674.e1-674.e6, 2016

17. Isaacson B, Berryhill W, Arts HA: Giant-cell tumors of the temporal bone: management strategies. Skull Base 19:291301, 2009

18. Jain S, Sam A, Yohannan DI, Kumar S, Joshi D, Kumar A: Giant cell tumor of the temporal bone-an unusual presentation. Clin Neurol Neurosurg 115:646-648, 2013

19. Kamoshima Y, Sawamura Y, Imai T, Furukawa H, Kubota K, Houkin K: Giant cell tumor of the frontal bone in a girl: case report. Neurol Med Chir (Tokyo) 51:798-800, 2011

20. Karamanakos PN, Jaaskelainen JE, Alafuzoff I, Pirinen E, Vanninen R, Silvennoinen S, et al: Malignant giant cell tumor in the posterior fossa of a neonate. J Neurosurg Pediatr 5:277-282, 2010

21. Kashiwagi N, Hirabuki N, Andou K, Yoshifumi N, Tanaka $\mathrm{H}$, Morino $\mathrm{H}$, et al: MRI and CT findings of the giant cell tumors of the skull; five cases and a review of the literature. Eur J Radiol 58:435-443, 2006

22. Kim IY, Jung S, Jung TY, Moon KS, Jang WY, Park SJ, et al: Gamma knife radiosurgery for giant cell tumor of the petrous bone. Clin Neurol Neurosurg 114:185-189, 2012

23. Lee MY, Lee EJ: Giant cell tumor of the petrous temporal bone with direct invasion into the middle ear. J Craniofac Surg 17:797-800, 2006 
24. Lu ZH, Yao ZW: Giant cell tumour of the posterior cranial fossa: a case report. Br J Radiol 84:e206-e209, 2011

25. Malone S, O'Sullivan B, Catton C, Bell R, Fornasier V, Davis A: Long-term follow-up of efficacy and safety of megavoltage radiotherapy in high-risk giant cell tumors of bone. Int $\mathbf{J}$ Radiat Oncol Biol Phys 33:689-694, 1995

26. Matsushige T, Nakaoka M, Yahara K, Kagawa K, Miura H, Ohnuma H, et al: Giant cell tumor of the temporal bone with intratumoral hemorrhage. J Clin Neurosci 15:923-927, 2008

27. Motomochi M, Handa Y, Makita Y, Hashi K: Giant cell tumor of the skull. Surg Neurol 23:25-30, 1985

28. Nicoli TK, Saat R, Kontio R, Piippo A, Tarkkanen M, Tarkkanen J, et al: Multidisciplinary approach to management of temporal bone giant cell tumor. J Neurol Surg Rep 77:e144e149, 2016

29. Omura S, Mizuki N, Bukawa H, Fujita K: Diffuse variant tenosynovial giant cell tumor of the temporomandibular joint: report of a case. J Oral Maxillofac Surg 56:991-996, 1998

30. Patibandla MR, Thotakura AK, Rao MN, Addagada GC, Nukavarapu MC, Panigrahi MK, et al: Clival giant cell tumora rare case report and review of literature with respect to current line of management. Asian J Neurosurg 12:78-81, 2017

31. Prasad SC, Piccirillo E, Nuseir A, Sequino G, De Donato G, Paties CT, et al: Giant cell tumors of the skull base: case series and current concepts. Audiol Neurotol 19:12-21, 2014

32. Present D, Bertoni F, Hudson T, Enneking WF: The correlation between the radiologic staging studies and histopathologic findings in aggressive stage 3 giant cell tumor of bone. Cancer 57:237-244, 1986

33. Quadros RS, de Sousa AA, Carvalho GT, Dellaretti Filho MA: Multifocal osteoclastoma of the skull: case report. Arq Neuropsiquiatr 62:167-169, 2004

34. Rock JP, Mahmood A, Cramer HB: Giant cell tumor of the skull base. Am J Otol 15:268-272, 1994

35. Roeder F, Timke C, Zwicker F, Thieke C, Bischof M, Debus $\mathrm{J}$, et al: Intensity modulated radiotherapy (IMRT) in benign giant cell tumors - a single institution case series and a short review of the literature. Radiat Oncol 5:18, 2010

36. Roy S, Joshi NP, Sigamani E, Malik A, Sharma MC, Mohanti $\mathrm{BK}$, et al: Clival giant cell tumor presenting with isolated trigeminal nerve involvement. Eur Arch Otorhinolaryngol 270:1167-1171, 2013

37. Sam JE, Rachmat RPN, Melano CSJ, Wahab NA: Giant cell tumor of temporomandibular joint masquerading as temporomandibular joint pain dysfunction syndrome: a rare case report. J Korean Assoc Oral Maxillofac Surg 43:134-137, 2017

38. Sharma RR, Mahapatra AK, Pawar SJ, Sousa J, Dev EJ: Craniospinal giant cell tumors: clinicoradiological analysis in a series of 11 cases. J Clin Neurosci 9:41-50, 2002

39. Spallone A, Flores GL, Zaldivar LO, Estupinan B: Giant cell tumor (osteoclastoma) of the petrous bone: case report. Skull Base Surg 9:155-159, 1999
40. Tamura R, Miwa T, Shimizu K, Mizutani K, Tomita H, Yamane N, et al: Giant cell tumor of the skull: review of the literature. J Neurol Surg A Cent Eur Neurosurg 77:239-246, 2016

41. Tse LF, Wong KC, Kumta SM, Huang L, Chow TC, Griffith JF: Bisphosphonates reduce local recurrence in extremity giant cell tumor of bone: a case-control study. Bone 42:68-73, 2008

42. Weber AL, Hug EB, Muenter MW, Curtin HD: Giant-cell tumors of the sphenoid bone in four children: radiological, clinical, and pathological findings. Skull Base Surg 7:163173,1997

43. Yamamoto M, Fukushima T, Sakamoto S, Tomonaga M: Giant cell tumor of the sphenoid bone: long-term follow-up of two cases after chemotherapy. Surg Neurol 49:547-552, 1998

44. Zhang Z, Xu J, Yao Y, Chu S, Cheng H, Chen D, et al: Giant cell tumors of the skull: a series of 18 cases and review of the literature. J Neurooncol 115:437-444, 2013

\section{Disclosures}

The authors report no conflict of interest concerning the materials or methods used in this study or the findings specified in this paper.

\section{Author Contributions}

Conception and design: JT Zhang, Weng, D Li, Wu, JM Wang, GL Li, Jia, LW Zhang. Acquisition of data: Weng, D Li, L Wang, JM Wang, GL Li. Analysis and interpretation of data: JT Zhang, Weng, D Li, L Wang, Wu, GL Li, Jia, LW Zhang. Drafting the article: Weng, D Li, L Wang, LW Zhang. Critically revising the article: all authors. Reviewed submitted version of manuscript: all authors. Approved the final version of the manuscript on behalf of all authors: JT Zhang. Statistical analysis: Weng, D Li, L Wang, Wu, GL Li, Jia, LW Zhang. Administrative/technical/material support: all authors. Study supervision: all authors.

\section{Supplemental Information \\ Online-Only Content}

Supplemental material is available with the online version of the article.

Supplementary Tables 1-4. https://thejns.org/doi/suppl/10. 3171/2018.4.JNS1849.

\section{Correspondence}

Jun-Ting Zhang: Beijing Tiantan Hospital, Capital Medical University, Beijing, People's Republic of China. zhangjunting2003@ aliyun.com. 